\title{
NERAPAN BALANCED SCORECARD SEBAGAI ALAT UKUR KINERJA PADA RUMAH SAKIT UMUM DAERAH Dr.HARJONO PONOROGO
}

\author{
Zaskia Tristiana Anggraini dan Elva Nuraina \\ Program Studi Pendidikan Akuntansi - FPIPS \\ IKIP PGRI MADIUN \\ elvanuraina99@gmail.com
}

\begin{abstract}
ABSTRAK
Rumah Sakit Umum Daerah Dr.Harjono Ponorogo merupakan rumah sakit rujukan pelayanan kesehatan di daerah sekitar Kota Ponorogo. Pengukuran kinerja rumah sakit didasarkan pada standar nasional pelayanan yang sudah ditentukan oleh pemerintah yaitu hanya menilai kinerja dari aspek keuangan. Untuk itu diperlukan adanya pengukuran kinerja dengan menggunakan Balanced Scorecard, dimana alat pengukuran kinerja ini mencakup semua aspek yang kemudian dikelompokkan menjadi empat perspektif utama yaitu: perspektif keuangan, perspektif pertumbuhan dan pembelajaran, perspektif proses bisnis internal, serta perspektif pelanggan. Tujuan penelitian ini adalah untuk mengetahui penerapan balanced scorecard yang ditinjau dari perspektif keuangan, perspektif pelanggan, perspektif proses bisnis internal serta perspektif pembelajaran dan pertumbuhan sebagai alat ukur kinerja pada Rumah Sakit Umum Daerah Dr.Harjono Ponorogo.

Pengujian penelitian ini untuk mengukur kinerja RSUD Dr.Harjono, analisis kinerja dilakukan dengan menggunakan metode Balanced Scorecard yang ditinjau dari perspektif keuangan, perspektif pelanggan, perspektif proses bisnis internal serta perspektif pembelajaran dan pertumbuhan. Pendekatan yang dilakukan dalam penelitian ini adalah melalui penelitian kombinasi dengan jenis data ordinal. Penelitian ini dilakukan dengan menggunakan data primer tahun 2011-2013 pada RSUD Dr.Harjono Ponorogo untuk menganalisis prespektif keuangan, pelanggan, proses bisnis internal, serta prespektif pembelajaran dan pertumbuhan, sedangkan pada tingkat kepuasan karyawan dilakukan analisis melalui kuisioner.

Hasil dari keseluruhan pengukuran kinerja dengan menggunakan balanced scorecard pada RSUD Dr.Harjono Ponorogo pada tahun 2011-2013 berada dalam kondisi Sangat Sehat kategori A dengan total score 76,24\%. Hasil analisis yang dilakukan, dapat diketahui bahwa kinerja RSUD Dr.Harjono menunjukan hasil cukup baik pada prespektif keuangan tapi perlu ditingkatkan pada rasio efisiensi, pada prespektif pelanggan menunjukkan hasil yang cukup baik pada tingkat customer retention namun pada tingkat profitabilitas pelanggan dan customer aquisition menunjukan hasil yang kurang baik, pada prespektif proses bisnis internal menunjukkan hasil cukup baik, demikian juga pada prespektif pembelajaran dan pertumbuhan menunjukkan hasil yang baik dengan tingkat kepuasan karyawan 69,08\%. Dari data penelitian tersebut dapat diambil kesimpulan bahwa dengan menggunakan balanced scorecard, rumah sakit dapat mengukur kinerja dengan lebih komprehensif, sehingga dapat meningkatkan kinerja dimasa yang akan datang.
\end{abstract}

Kata Kunci : Balanced Scorecard, Alat Ukur Kinerja, RSUD Dr.Harjono 


\section{PENDAHULUAN}

Pentingnya pelayanan rumah sakit yang bermutu dan berkualitas harus semakin ditingkatkan seiring dengan semakin meningkatnya pertumbuhan penduduk dan derajat kesehatan masyarakat. Setiap unit usaha dituntut untuk meningkatkan mutu dan bekerja lebih efektif dan efisien agar mendaptkan hasil yang optimal sehingga tetap eksis didunia usaha. Dari segi pelayanan, rumah sakit merupakan organisasi sektor publik yang memberikan pelayanan secara medis.

Menurut Mardiasmo (2002: 2) bahwa istilah "sektor publik" sendiri memiliki pengertian bermacam-macam. Hal tersebut merupakan konsekuensi dari luasnya wilayah publik, sehingga setiap disiplin ilmu (ekonomi, polotik, hukum, dan sosial) memiliki cara pandang dan definisi yang berbeda-beda. Dari sudut pandang ekonomi, sector public dapat dipahami sebagai suatu entitas yang aktivitasnya berhubungan dengan usaha untuk menghasilkan barang dan pelayanan public dalam rangka memenuhi kebutuhan dan hak publik.

Rumah sakit dituntut untuk mampu memberikan pelayanan memuaskan, profesional dengan harga bersaing, sehingga strategi dan kinerja rumah sakit tersebut harus berfokus pada keinginan pelanggan (pasien) tersebut. Penilaian atau pengukuran kinerja merupakan salah satu faktor yang penting dalam perusahaan. Selain digunakan untuk menilai keberhasilan perusahaan, pengukuran kinerja juga dapat digunakan sebagai dasar untuk mengevaluasi hasil kerja dari periode yang lalu.

Selama ini, pengukuran kinerja perusahaan cenderung lebih memfokuskan terhadap sisi keuangan saja. Sementara itu, metode pengukuran kinerja telah berkembang pesat. Pengukuran kinerja perusahaan tidak lagi dianggap baik jika hanya dilihat dari sisi keuangan saja yang tidak mampu mencerminkan kompleksitas dan nilai yang melekat pada perusahaan, karena tidak memperhatikan hal-hal lain di luar finansial, yaitu sisi pelanggan dan karyawan yang merupakan faktor penting bagi perusahaan. Pengukuran kinerja dalam suatu perusahaan tidak hanya dilihat dari segi keuangan saja, tapi akan lebih baik apabila dari segi non keuangan juga diukur untuk memaksimalkan kinerja suatu perusahaan.

Dor dan Maryanne (2009: 366) mengungkapkan bahwa balanced scorecard menerjemahkan misi dan strategi organisasi dalam tujuan operasional dan ukuran kinerja dalam empat perspektif, yaitu perspektif keuangan, perspektif pelanggan, perspektif proses bisnis internal, serta perspektif pembelajaran dan pertumbuhan. Dengan peranan yang dimainkan keempat perspektif ini dalam ukuran kinerja, pengujian perspektif yang lebih detail akan lebih terjamin.

Rumah Sakit Umum Daerah Dr.Harjono Ponorogo merupakan rumah sakit rujukan pelayanan kesehatan di daerah sekitar Kota Ponorogo. Oleh karena itu untuk dapat memberikan pelayanan kesehatan yang berkualitas bagi masyarakat perlu disusun visi, misi, tujuan, sasaran serta indikator keberhasilan yang diselesaikan dalam bentukrencana strategis. Indikator keberhasilan bukan saja dalam bentuk finansial tapi juga dengan indikator yang lain seperti pelangan, bisnis internal juga pembelajaran dan pertumbuhan yang selanjutnya dijadikan bahan untuk mengendalikan arah dan mutu pelayanan kesehatan agar visi yang telah ditetapkan benar-benar dapat diwujudkan.

Pengukuran kinerja rumah sakit didasarkan pada standar nasional pelayanan yang sudah ditentukan oleh pemerintah yaitu hanya menilai kinerja dari 
aspek keuangan. Untuk itu diperlukan adanya pengukuran kinerja dengan menggunakan Balanced Scorecard, dimana alat pengukuran kinerja ini mencakup semua aspek yang kemudian dikelompokkan menjadi empat perspektif utama yaitu: perspektif keuangan, perspektif pertumbuhan dan pembelajaran, perspektif proses bisnis internal, serta perspektif pelanggan. Dari latar belakang di atas, maka dalam penelitian ini peneliti tertarik untuk membahas mengenai "Penerapan Balanced Scorecard Sebagai Alat Ukur Kinerja pada Rumah Sakit Umum Daerah Dr.Harjono Ponorogo".

\section{Tujuan penelitian:}

1. Mengetahui pengukuran kinerja Rumah Sakit Umum Daerah Dr.Harjono.

2. Mengetahui penerapan balanced scorecard yang ditinjau dari perspektif keuangan, perspektif pelanggan, perspektif proses bisnis internal serta perspektif pembelajaran dan pertumbuhan sebagai alat ukur kinerja pada Rumah Sakit Umum Daerah Dr.Harjono Ponorogo.

3. Mengetahui tingkat kepuasan karyawan terhadap kinerja manajemen Rumah Sakit Umum Daerah Dr.Harjono Ponorogo.

4. Menganalisis perbandingan antara pengukuran kinerja tradisional dengan pengukuran kinerja menggunakan Balanced Scorecard.

\section{KAJIAN TEORI}

Moeheriono (2010: 61) berpendapat bahwa kinerja adalah hasil kerja yang dapat dicapai oleh seseorang atau sekelompok orang dalam suatu organisasi baik secara kuantitatif maupun kuaitatif sesuai dengan kewenangan dan tugas tanggungjawab masing-masing dalam upaya mencapai tujuan organisasi bersangkutan secara ilegal, tidak melanggar hukum dan sesuai dengan moral maupun etika.

Pengukuran kinerja (performance measurement) mempunyai penilaian suatu proses penilaian tentang kemajuan pekerjaan terhadap tujuan dan sasaran dalam pengelolaan sumber daya manusia untuk menghasilkan barang dan jasa termasuk efisiensi serta efektivitas tindakan dalam mencapai tujuan organisasi (Moeheriono, 2010: 61). Menurut Mulyadi (2007: 3) bahwa Balanced Scorecard terdiri dari 2 suku kata yaitu kartu nilai (scorecard) dan balanced (berimbang). Pada tahap eksperimen awal, Balanced Scorecard merupakan kartu skor yang dimanfaatkan untuk mencatat skor hasil kerja eksekutif. Melalui kartu skor, skor yang hendak diwujudkan eksekutif di masa depan dibandingkan dengan hasil kinerja sesungguhnya. Hasil perbandingan ini dimanfaatkan untuk melakukan evaluasi atas kinerja eksekutif. Kata berimbang dimaksudkan untuk menunjukkan bahwa kinerja eksekutif diukur secara berimbang dari dua perspektif: keuangan dan nonkeuangan, jangka pendek dan jangka panjang, intern dan ekstern.

Dor dan Maryanne (2009: 366) mengungkapkan bahwa balanced scorecard menerjemahkan misi dan strategi organisasi dalam tujuan operasional dan ukuran kinerja dalam empat perspektif, yaitu perspektif keuangan, perspektif pelanggan, perspektif proses bisnis internal, serta perspektif pembelajaran dan pertumbuhan. Dengan peranan yang dimainkan keempat perspektif ini dalam ukuran kinerja, pengujian perspektif yang lebih detail akan lebih terjamin. Mulyadi (2007: 15) berpendapat bahwa keunggulan pendekatan Balanced 
Scorecard dalam sistem perencanaan strategik yang memiliki karakteristik sebegai berikut :
a. Komprehensif
b. Koheren
c. Berimbang
d. Terukur

\section{METODE PENELITIAN}

Penelitian ini dilakukan pada Rumah Sakit Umum Daerah Dr.Harjono karena merupakan rumah sakit rujukan pelayanan kesehatan di daerah sekitar Kota Ponorogo, oleh karena itu harus dapat memberikan pelayanan kesehatan yang berkualitas bagi masyarakat yang sesuai dengan visi, misi, tujuan strategis.

Pendekatan penelitian dilakukan adalah melalui penelitian Kombinasi. Jenis data yang digunakan adalah data ordinal. Menurut Sugiyono (2013: 28) bahwa data ordinal merupakan data kuantitatif yang berbentuk peringkat atau rangking. Menurut Sugiyono (2013: 271) bahwa metode penelitian kombinasi adalah suatu metode penelitian yang mengkombinasikan atau menggabungkanantara metode kuantitatif dan metode kualitatif untuk digunakan secara bersama-sama dalam suatu kegiatan penelitian, sehingga diperoleh data yang lebih komprehensif, valid, reliabel dan objektif.

Sumber data yang digunakan dalam penelitian ini berupa data primer dan data sekunder. Sumber data primer yang digunakan dalam penelitian ini diperoleh dari hasil wawancara dengan pihak perusahaan, data perusahaan seperti data laporan keuangan, anggaran pendapatan dan pengeluaran, data jumlah pasien (lama, baru, hidup dan mati), jumlah tempat tidur, data jumlah karyawan, serta dari hasil penyebaran kuisioner yang dilakukan peneliti. Sedangkan sumber data sekunder yang digunakan dalam penelitian ini seperti visi, misi dan sejarah berdirinya rumah sakit(www.rsudrharjono.or.id).

Metode yang digunakan untuk mengumpulkan data yaitu dengan menggunakan metode kuesioner, wawncara, observasi, dokumentasi dan studi pustaka. Koesioner yang disebarkan kepada karyawan rumah sakit digunakan untuk mengukur kepuasan karyawan dalam perspektif pembelajaran dan pertumbuhan, tehnik keabsahan data yang digunakaaaaan adalah menggunakan uji validitas dan reliabilitas. Teknik analisis data yang digunakan adalah:

1. Perspektif Keuangan, Rasio yang digunakan adalah:

a. Rasio ekonomis.

b. Rasio efisiensi.

c. Rasio efektivitas.

2. Perspektif Pelanggan

a. Tingkat profitabilitas pelanggan.

b. Kemampuan mempertahankan pelanggan (Customer Retention).

c. Kemampuan meraih pelanggan baru (Customer Aquisition).

3. Perspektif Proses Bisnis Internal, rantai nilai proses terdiri dari dua proses yaitu:

a. Proses Inovasi.

b. Proses Operasional. 
4. Perspektif Pembelajaran Dan Pertumbuhan, ukuran kinerja yang dipakai adalah:
a. Kepuasan karyawan.
b. Retensi karyawan.
c. Produktivitas karyawan.

\section{PEMBAHASAN}

Konsep balanced scorecard dalam mengukur kinerja RSUD Dr.Harjono Ponorogo yang menggunakan empat prespektif yaitu: prespektif keuangan, pelanggan, proses bisnis internal serta pertumbuhan dan pembelajaran, dari tiaptiap prespektif balanced scorecard tersebut, terdapat beberapa strategi yang diperoleh dari observasi dan wawancara dengan beberapa bagian di RSUD Dr.Harjono Ponorogo.

1. Perspektif Keuangan

Tabel 1 Rekapitulasi perhitungan rasio ekonomi RSUD Dr.Harjono Ponorogo

tahun 2011-2013

\begin{tabular}{|l|l|l|l|l|}
\hline \multirow{2}{*}{ Tahun } & Realisasi & Anggaran & $\begin{array}{l}\text { Rasio } \\
\text { Ekonomi }(\%)\end{array}$ & $\begin{array}{l}\text { Naik/Turun } \\
(\%)\end{array}$ \\
\cline { 2 - 5 } & $(1)$ & $(2)$ & $(3)=(1):(2)$ & - \\
\hline 2011 & 43.523 .654 .638 & 43.429 .033 .000 & $100,22 \%$ & - \\
\hline 2012 & 80.211 .062 .540 & $78.255 .197 .877,21$ & $102,50 \%$ & Naik 2,28\% \\
\hline 2013 & 96.246 .670 .583 & $98.525 .499 .535,06$ & $97,69 \%$ & Turun $4,81 \%$ \\
\hline
\end{tabular}

Sumber: Data yang diolah

Tabel 2 Rekapitulasi perhitungan rasio efisiensi RSUD Dr.Harjono tahun 2011-2013

\begin{tabular}{|l|l|l|l|l|}
\hline \multirow{2}{*}{ Tahun } & Realisasi Biaya & $\begin{array}{l}\text { Realiasai } \\
\text { Pendapatan }\end{array}$ & $\begin{array}{l}\text { Rasio } \\
\text { Efisiensi }(\%)\end{array}$ & $\begin{array}{l}\text { Naik/Turun } \\
(\%)\end{array}$ \\
\cline { 2 - 5 } & $(1)$ & $(2)$ & $(3)=(1):(2)$ & \\
\hline 2011 & 43.523 .654 .638 & $28.657 .395 .879,83$ & $151,88 \%$ & - \\
\hline 2012 & 80.211 .062 .540 & $60.209 .097 .247,85$ & $133,21 \%$ & Naik 18,67\% \\
\hline 2013 & 96.246 .670 .583 & $68.006 .102 .818,85$ & $141,52 \%$ & Naik 8,31\% \\
\hline
\end{tabular}

Sumber: Data yang diolah

Tabel 3 Rekapitulasi perhitungan rasio efektivitas RSUD Dr.Harjono Ponorogo tahun 2010-2012

\begin{tabular}{|c|l|l|l|l|}
\hline \multirow{2}{*}{ Tahun } & \multicolumn{1}{|c|}{$\begin{array}{c}\text { Anggaran } \\
\text { Pendapatan }\end{array}$} & $\begin{array}{l}\text { Realisasi } \\
\text { Pendapatan }\end{array}$ & $\begin{array}{l}\text { Rasio } \\
\text { Efektivitas }\end{array}$ & $\begin{array}{l}\text { Naik/Turun } \\
(\%)\end{array}$ \\
\cline { 2 - 4 } & $(1)$ & $(2)$ & $(3)=(1):(2)$ & \\
\hline 2011 & 26.584 .362 .000 & $28.657 .379,83$ & $92,77 \%$ & - \\
\hline 2012 & 49.000 .000 .000 & $60.209 .097 .247,85$ & $81,38 \%$ & $\begin{array}{l}\text { Turun } \\
11,39 \%\end{array}$ \\
\hline 2013 & $68.006 .102 .818,85$ & 60.000 .000 .000 & $88,22 \%$ & Naik 6,84\% \\
\hline
\end{tabular}

Sumber: Data yang diolah 
2. Perspektif Pelanggan

Tabel 4 Rekapitulasi hasil pengukuran Kinerja Prespektif Pelanggan RSUD

Dr.Harjono Ponorogo tahun 2011 - 2013

\begin{tabular}{|c|c|c|c|c|c|c|}
\hline \multirow[b]{2}{*}{ Tahun } & \multicolumn{6}{|l|}{ Ukuran } \\
\hline & $\begin{array}{c}\text { Profitabilitas } \\
\text { Pelanggan } \\
\end{array}$ & $\begin{array}{l}\text { Naik } \\
\text { /turun }\end{array}$ & $\begin{array}{l}\text { Customer } \\
\text { Retention }\end{array}$ & $\begin{array}{l}\text { Naik } \\
\text { /turun }\end{array}$ & $\begin{array}{l}\text { Costomer } \\
\text { Aquisition }\end{array}$ & $\begin{array}{l}\text { Naik } \\
\text { /turun }\end{array}$ \\
\hline \multirow[b]{2}{*}{2011} & $96,66 \%$ & - & $59,08 \%$ & - & $62,87 \%$ & - \\
\hline & $95,72 \%$ & $-0,94 \%$ & $156,80 \%$ & $+97,72 \%$ & $38,90 \%$ & - \\
\hline \multirow{2}{*}{2012} & $95,60 \%$ & $-0,12 \%$ & $166,96 \%$ & $+10,16 \%$ & & 23,97 \\
\hline & & & & & $37,46 \%$ & \\
\hline 2013 & & & & & & $-\overline{1,44 \%}$ \\
\hline
\end{tabular}

Sumber: data diolah peneliti

3. Perspektif Proses Bisnis Internal

Tabel 5 Proses Inovasi RSUD Dr.Harjono Ponorogo tahun 2011-2013

\begin{tabular}{|l|c|c|c|}
\hline Tahun & Pendapatan Jasa Baru & Total Pendapatan & Inovasi (\%) \\
\hline 2011 & $\operatorname{Rp~} 896.784 .812,6$ & $\operatorname{Rp} 28.896 .159 .079,83$ & $3,10 \%$ \\
\hline 2012 & $\operatorname{Rp~} 1.991 .353 .661 .43$ & $\operatorname{Rp~} 49.749 .811 .097,45$ & $4,002 \%$ \\
\hline 2013 & $\operatorname{Rp} 3.030 .979 .381,48$ & $\operatorname{Rp~72.894.843.928,26~}$ & $4,15 \%$ \\
\hline
\end{tabular}

Sumber: RSUD Dr.Harjono Ponorogo yang telah diolah

Pada proses operasional, pengukuran kinerja menggunakan skor 1 yang berarti baik dan -1 yang berarti kurang baik

Tabel 6 Skor pengukuran kinerja RSUD Dr.Harjono

\begin{tabular}{|c|c|}
\hline Indikator & Skor \\
\hline Rawat Jalan & -1 \\
\hline Rawat Inap & 1 \\
\hline BOR & 1 \\
\hline ALOS & -1 \\
\hline TOI & 1 \\
\hline BTO & -1 \\
\hline GDR & 1 \\
\hline NDR & 1 \\
\hline Total Skor & $\mathbf{2}$ \\
\hline
\end{tabular}

Sumber : Data sekunder diolah

4. Perspektif Pembelajaran dan Pertumbuhan

Tabel 7 Rekapitulasi hasil pengukuran Kinerja Perspektif Pembelajaran dan Pertumbuhan RSUD Dr.Harjono tahun 2011 - 2013

\begin{tabular}{|l|l|l|c|}
\hline \multirow{2}{*}{ Tahun } & Ukuran & \multicolumn{3}{|l|}{$\begin{array}{l}\text { Kepuasan } \\
\text { karyawan }\end{array}$} & $\begin{array}{l}\text { Retensi } \\
\text { karyawan }\end{array}$ & Produktivitas karyawan \\
\hline 2011 & - & $1,2 \%$ & $\mathrm{Rp} \mathrm{58.024.415,8}$ \\
\hline 2012 & - & $0,86 \%$ & $\mathrm{Rp} \mathrm{86.371.199,81}$ \\
\hline 2013 & $69,08 \%$ & $0,85 \%$ & $\mathrm{Rp} \mathrm{124.182.016,9}$ \\
\hline
\end{tabular}

Sumber: data diolah peneliti 
Dengan indeks kepuasan yang dihasilkan demikian maka pengukuran kepuasan karyawan RSUD Dr.Harjono masuk dalam kategori puas untuk kebijakan perusahaan, gaji maupun keseluruhan perusahaan.

Hasil pengukuran kinerja perusahaan dengan Balanced Scorecard Tabel 8 Pengukuran Bobot Indikator dan Skor Tertimbang maksimal

\begin{tabular}{|c|c|c|c|c|c|c|}
\hline Prespektif & $\begin{array}{c}\text { Indikator } \\
\text { Kerja }\end{array}$ & $\begin{array}{c}\text { Jumlah } \\
\text { Indikator }\end{array}$ & Bobot & $\begin{array}{c}\text { Bobot } \\
\text { Indikator }\end{array}$ & $\begin{array}{c}\text { Skor } \\
\text { Indikator }\end{array}$ & $\begin{array}{c}\text { Skor } \\
\text { Tertimbang } \\
\text { Maksimal }\end{array}$ \\
\hline \multirow{3}{*}{ Keuangan } & R.Ekonomi & 3 & 26 & 8,66 & 4 & 103,92 \\
\hline & R.Efisiensi & & & & & \\
\hline & R.Efektivitas & & & & & \\
\hline \multirow{3}{*}{ Pelanggan } & Prifitabilitas & 3 & 25 & 8,33 & 4 & 99,96 \\
\hline & Retention & & & & & \\
\hline & Aquisition & & & & & \\
\hline \multirow{2}{*}{$\begin{array}{l}\text { Proses Bisnis } \\
\text { Internal }\end{array}$} & Inovasi & 2 & 24 & 12 & 4 & 96 \\
\hline & Operasional & & & & & \\
\hline \multirow{3}{*}{$\begin{array}{l}\text { Pembelajaran } \\
\text { dan } \\
\text { Pertumbuhan }\end{array}$} & Kepuasan & 3 & 25 & 8,33 & 4 & 99,96 \\
\hline & Retensi & & & & & \\
\hline & Produktivitas & & & & & \\
\hline & Total & & 100 & & & 399,84 \\
\hline
\end{tabular}

Sumber: Data diolah peneliti

Tahap selanjutnya adalah mengukur jumlah skor indikator keuangan dan memebrikan nilai $\mathrm{A}=4, \mathrm{~B}=3, \mathrm{C}=2, \mathrm{D}=1$ dan untuk perspektif keuangan ditentukan sebagai berikut:

1. Nilai target rasio ekonomi $=175 \%$

Nilai minimum $=0$

Interval kelas rasio ekonomi $=(175-0) / 3=58,33 \%$

Jadi kriteria skor indikator rasio ekonomi adalah:

$\mathrm{A}=116,67 \%-175 \%$

$\mathrm{B}=58,34 \%-<116,67 \%$

$\mathrm{C}=0,01 \%-<58,34 \%$

$\mathrm{D}=<0,01 \%$

2. Nilai target rasio efisiensi $=35 \%$

Nilai minimum $=0$

Interval kelas rasio efisiensi $=(35-0) / 3=11,66 \%$

Jadi kriteria skor indikator rasio efisiensi adalah:

$\mathrm{A}=23,34 \%-35 \%$

$\mathrm{B}=11,68 \%-<23,34 \%$

$\mathrm{C}=0,02 \%-<16,68 \%$

$\mathrm{D}=<0,02 \%$

3. Nilai target rasio efektivitas $=40 \%$

Nilai minimum $=0$

Interval kelas rasio efektivitas $=(40-0) / 3=13,33 \%$

Jadi kriteria skor indikator rasio efektivitas adalah:

$\mathrm{A}=26,67 \%-40 \%$

$\mathrm{B}=13,34 \%-<26,67 \%$

$\mathrm{C}=0,01 \%-<13,34 \%$

$\mathrm{D}=<0,01 \%$ 
Tabel 9 Nilai Untuk Masing-Masing Indikator Dalam Perspektif Balanced Scorecard RSUD Dr.Harjono Tahun 2011- 2013

\begin{tabular}{|c|c|c|c|c|c|c|}
\hline \multirow{2}{*}{ Prespektif } & \multicolumn{3}{|l|}{ Tahun } & \multirow{2}{*}{$\begin{array}{l}\text { Rata- } \\
\text { rata }\end{array}$} & \multirow{2}{*}{$\begin{array}{l}\text { Nila } \\
\text { i }\end{array}$} & \multirow{2}{*}{$\begin{array}{l}\text { Skor } \\
\text { Indokator }\end{array}$} \\
\hline & 2011 & 2012 & 2013 & & & \\
\hline \multicolumn{7}{|l|}{ Keuangan: } \\
\hline Rasio Ekonomi & $100,22 \%$ & $102,50 \%$ & $97,69 \%$ & $100,13 \%$ & $\mathrm{~B}$ & 3 \\
\hline Rasio Efisiensi & $151,88 \%$ & $133,21 \%$ & $141,52 \%$ & $142,20 \%$ & $\mathrm{~A}$ & 4 \\
\hline $\begin{array}{l}\text { Rasio } \\
\text { Efektivitas }\end{array}$ & $92,77 \%$ & $81,38 \%$ & $88,22 \%$ & $87,45 \%$ & $\mathrm{~B}$ & 3 \\
\hline \multicolumn{6}{|l|}{ Total } & 10 \\
\hline \multicolumn{7}{|l|}{ Pelanggan: } \\
\hline Profitabilitas & $96,66 \%$ & $95,72 \%$ & $95,60 \%$ & $95,99 \%$ & $\mathrm{~B}$ & 3 \\
\hline $\begin{array}{l}\text { Customer } \\
\text { Retention }\end{array}$ & $59,08 \%$ & $156,80 \%$ & $166,96 \%$ & $127,61 \%$ & $\mathrm{~A}$ & 4 \\
\hline $\begin{array}{l}\text { Customer } \\
\text { Aquisition }\end{array}$ & $62,87 \%$ & $38,90 \%$ & $37,46 \%$ & $46,41 \%$ & $\mathrm{C}$ & 2 \\
\hline \multicolumn{6}{|l|}{ Total } & 9 \\
\hline \multicolumn{7}{|l|}{$\begin{array}{l}\text { Bisnis } \\
\text { Internal: }\end{array}$} \\
\hline Inovasi & $3,10 \%$ & $4,002 \%$ & $4,15 \%$ & $3,75 \%$ & $\mathrm{C}$ & 2 \\
\hline Operasional & & & & & $\mathrm{B}$ & 3 \\
\hline \multicolumn{6}{|l|}{ Total } & 5 \\
\hline \multicolumn{7}{|l|}{$\begin{array}{l}\text { Pembelajaran } \\
\text { \& } \\
\text { Pertumbuhan: }\end{array}$} \\
\hline Kepuasan & & & $69,08 \%$ & & $\mathrm{~B}$ & 3 \\
\hline Retensi & $1,2 \%$ & $0,86 \%$ & $0,85 \%$ & $4,57 \%$ & $\mathrm{~B}$ & 3 \\
\hline Produktivitas & $\begin{array}{l}\mathrm{Rp} \\
58.024 .415,8\end{array}$ & $\begin{array}{l}\mathrm{Rp} \\
86.371 .199 \\
81\end{array}$ & $\begin{array}{l}\mathrm{Rp} \\
124.182 .0 \\
16,9\end{array}$ & & A & 4 \\
\hline Total & & & & & & 10 \\
\hline
\end{tabular}

Sumber: Data diolah peneliti

Tahap selanjutnya adalah menghitung jumlah skor tertimbang dengan mengalikan jumlah skor indikator dengan bobot indikator sehingga hasilnya dapat dilihat seperti pada tabel dibawah ini:

Tabel 10 Jumlah Skor Tertimbang

\begin{tabular}{|l|l|l|l|}
\hline Prespektif & $\begin{array}{l}\text { Jumlah Skor } \\
\text { Tertimbang }\end{array}$ & Bobot indicator & Skor \\
\hline Keuangan & 10 & 8,66 & 86,6 \\
\hline Pelanggan & 9 & 8,33 & 74,97 \\
\hline Bisnis internal & 5 & 12 & 60 \\
\hline $\begin{array}{l}\text { Pembelajaran \& } \\
\text { Pertumbuhan }\end{array}$ & 10 & 8,33 & 83,3 \\
\hline Jumlah Skor Tertimbang & 304,87 \\
\hline
\end{tabular}

Sumber: Data diolah peneliti

Selanjutnya, jumlah skor tertimbang tersebut digunakan untuk menghitung nilai akhir total score. Dan untuk menghitung nilai akhir total atau total score digunakan rumus $=($ jumlah skor tertimbang $/$ jumlah skor tertimbang maksimum $)$ 
x 100\%. Sehingga diperoleh hasil total score $=(304,87 / 399,84) \times 100 \%=76,24$

$\%$. Kemudian dilihat dari kriteria standar:

Tabel 11 Kriteria Standar Penilaian

\begin{tabular}{|l|l|l|}
\hline Kondisi & Kategori & Total score \\
\hline SANGAT SEHAT & AAA & $\geq 95$ \\
\cline { 2 - 3 } & AA & $80<\mathrm{TS}<95$ \\
\cline { 2 - 3 } & $\mathrm{A}$ & $65<\mathrm{TS}<80$ \\
\hline \multirow{3}{*}{ KURANG SEHAT } & $\mathrm{BBB}$ & $50<\mathrm{TS}<65$ \\
\cline { 2 - 3 } & $\mathrm{BB}$ & $40<\mathrm{TS}<50$ \\
\cline { 2 - 3 } & $\mathrm{B}$ & $30<\mathrm{TS}<40$ \\
\hline TIDAK SEHAT & $\mathrm{CCC}$ & $20<\mathrm{TS}<30$ \\
\cline { 2 - 3 } & $\mathrm{CC}$ & $10<\mathrm{TS}<20$ \\
\cline { 2 - 3 } & $\mathrm{C}$ & $\mathrm{TS}<10$ \\
\hline
\end{tabular}

Sumber: Rangkuti Freddy (2011: 147)

Maka dapat ditarik kesimpulan hasil pengukuran kinerja dengan menggunakan Balanced Scorecard pada RSUD Dr.Harjono Ponorogo diperoleh nilai dengan total score 76,24\% sehingga masuk dalam kondisi Sangat Sehat kategori A.

\section{KESIMPULAN}

\section{Simpulan}

RSUD Dr.Harjono Ponorogo memungkinkan untuk menerapkan balanced scorecard karena hasil pengukuran kinerja yang dihasilkan peneliti di RSUD Dr.Harjono Ponorogo dengan menggunakan balance scorecard, dapat disimpulkan bahwa:

1. Hasil dari keseluruhan pengukuran kinerja dengan menggunakan balanced scorecard pada RSUD Dr.Harjono Ponorogo pada tahun 2011 sampai 2013 berada dalam kondisi Sangat Sehat kategori A dengan total score $76,24 \%$. Kategori puas tersebut didukung dengan peningkatan koordinasi, konsolidasi sesama karyawan, pemerintah dan lembaga masyarakat untuk mencapai kepentingan bersama melalui kerjasama dan komunikasi yang efektif. Peningkatan pengetahuan, kemampuan dan ketrampilan karyawan rumah sakit baik medis, paramedis maupun tenaga yang lain melalui pendidikan dan pelatihan baik didalam maupun diluar rumah sakit sebagai penghargaan terhadap prestasi kerja dan motivasi bekerja lebih baik dari sebelumnya.

2. Hasil pengukuran kinerja berdasarkan empat perspektif, yaitu:

a. Hasil pengukuran perspektif keuangan, yaitu Rasio Ekonomi dan Rasio Efektivitas menunjukkan hasil yang baik sedangkan Rasio Efisiensi menunjukkan hasil yang kurang baik karena realisasi biaya lebih besar dari tahun 2011-2013. Realisasi biaya tersebut digunakan untuk pemenuhan Belanja Operasi dan Belanja Modal.

b. Hasil pengukuran perspektif pelanggan, menunjukkan hasil yang baik pada tingkat Customer Retention karena dapat mempertahankan pelanggan dari tahun 2011-2013, namun pada tingkat Profitabilitas Pelanggan dan Customer Aquisition menunjukan hasil yang kurang baik karena terjadi penurunan persentase dari tahun 2011-2013, karena adanya perubahan tarif baru RSUD sehingga berpengaruh pada 
pendapatan dan juga ada keluhan pasien tentang kualitas pelayanan petugas.

c. Hasil pengukuran perspektif Proses Bisnis Internal, pada proses inovasi menunjukkan peningkatan persentase dari tahun 2011-2013, ini berarti hasilnya cukup baik karena setiap tahun selalu ada tambahan jasa baru dan juga pada proses operasional menunjukkan hasil yang cukup baik karena sudah sesuai dengan angka ideal yang ditetapkan.

d. Hasil pengukuran perspektif pembelajaran dan pertumbuhan juga menunjukkan hasil yang baik, dengan tingkat kepuasan karyawan $69,08 \%$, tingkat produktivitas karyawan juga menunjukkan hasil yang baik, hal ini dipengaruhi dari total pendapatan dan jumlah karyawan yang selalu meningkat dan juga melihat persentase tingkat retensi karyawan yang menurun dari tahun 2011-2013, tingkat persentase yang semakin menurun menunjukkan hasil yang cukup baik karena berarti jumlah karyawan meningkat sedangkan karyawan yang keluar berkurang.

3. Pengukuran kinerja RSUD Dr.Harjono dengan menggunakan balanced scorecard periode 3 tahun menunjukkan hasil yang berbeda dengan pengukuran kinerja secara tradisional yang dilakukan RSUD Dr.Harjono. dengan balanced scorecard, rumah sakit dapat mengukur kinerja dengan lebih komprehensif, sehingga dapat meningkatkan kinerja dimasa yang akan datang.

\section{Saran}

Berdasarkan hasil analisis dan kesimpulan yang diperoleh, saran-saran yang diajukan bagi penelitian-penelitian selanjutnya adalah:

1. Perspektif keuangan pada tingkat rasio efisiensi harus lebih memperhatikan pengeluaran biaya sehingga bila diperbandingkan tidak jauh lebih besar dari realisasi pendapatan yang ada yaitu dengan cara mengarahkan biaya untuk belanja kegiatan program-program RSUD Dr.Harjono yang dinilai prioritas dan sangat mendesak untuk segera direalisasikan.

2. Dari perspektif pelanggan, perlu meningkatkan profitabilitas pelanggan dengan lebih meningkatkan pelayanan kesehatan dan perlu meningkatkan tingkat pemerolehan pelanggan mengingat angka prosentase customer aquisition yang menurun pada tahun 2011-2013 salah satunya dengan menetapkan kebijakan yang dapat menarik minat pelanggan.

\section{DAFTAR PUSTAKA}

Bestari Dwi Handayani. 2011. Pengukuran Kinerja Rumah Sakit Umum Daerah dengan Pendekatan Balance Scorecard. Jurnal Dinamika Manajemen, 3(1): 74-89.

Dor Hansen dan Maryanne M. Mowen. 2009. Akuntansi Manajerial. Jakarta: Salemba Empat.

Freddy, Rangkuti. 2011. SWOT Balanced Scorecard (Teknik Menyusun Strategi Korporat yang Efektif plus Cara Mengeola Kinerja dan Risiko). Jakarta: Gramedia Pustaka Utama. 
Gaspersz, Vincent. 2003. Sistem Manajemen Kinerja Terintegrasi Balanced Scorecard Dengan Six Sigma Untuk Organisasi Bisnis Dan Pemerintah. Jakarta: PT Gramedia Pustaka Utama.

Imam Ghozali. 2006. Aplikasi Analisis Multivariate dengan Program SPSS. Semarang: Badan Penerbit Universitas Diponegoro.

Mardiasmo. 2002. Akuntansi Sektor Publik. Yogyakarta: ANDI Yogyakarta.

Moeheriono. 2010. Pengukuran Kinerja Berbasis Kompetensi. Bogor: Ghalia Indonesia.

Mulyadi. 2007. Sistem Terpadu Pengelolaan Kinerja Personel Berbasis Balanced Scorecard. Yogyakarta: Sekolah Tinggi Ilmu Manajemen YKPN.

Ni Ketut Rasmini, Ni Luh Supadmi, dan Ni Luh Putu Herawati Sucandra. 2009. Penilaian Kinerja Badan Rumah Sakit Umum Tabanan Berdasarkan Balanced Scorecard. Jurnal (Online), (http://ojs.unud.ac.id, Diunduh 20 Januari 2014).

Sugiyono. 2010. Metode Penelitian Pendidikan (Pendekatan Kuantitatif, Kualitatif, dan $R \& D)$. Bandung: Alfabeta,cv.

Sugiyono. 2011. Metode Penelitian Kuantitatif dan Kualitatif dan $R \& D$. Bandung: Alfabeta Bandung.

Sugiyono. 2013. Cara mudah menyusun: SKRIPSI, TESIS dan DISERTASI. Bandung: Alfabeta,cv.

Suharsimi Arikunto. 2010. Prosedur Penelitian Suatu Pendekatan Praktik. Jakarta: RINEKA CIPTA.

Wibowo. 2007. Manajemen Kinerja. Jakarta: PT Raja Grafindo Persada.

Yuwono Sony dkk. 2004. Petunjuk Praktis Penyusunan Balance Scorecard (Menuju Organisasi Yang Berfokus Pada Strategi). Jakarta: Gramedia Pustaka Utama. 